\title{
The Effect of Birth Order and Self-Concept Clarity toward Autonomous Learning
}

\author{
Rosleny Marliani ${ }^{1}$, Muhammad Ikbal Fadhlullah ${ }^{2}$, Fridayanti ${ }^{3}$ \\ Universitas Islam Negeri Sunan Gunung Djati Bandung, Bandung 40614, Indonesia
}

\{fridayanti@uinsgd.ac.id ${ }^{3}$ \}

\begin{abstract}
The aim of this study is to determine the effect of birth order and selfconcept clarity toward autonomous learning among college student. This study used quantitative approach and the data was analysed using covariance analysis (ANCOVA). The subjects of this study were 191 college students located in Bandung, West Java Indonesia. The measurements instruments were selfconcept clarity scale and autonomous learning scale. Research result shows that birth order and self-concept clarity simultaneously affect the autonomous learning.
\end{abstract}

Keywords : Birth order, self-concept and autonomous learing

\section{Introduction}

The transition from high school to college can put young adults in vulnerable situations. College life can be demanding and stressful. Study at university requires students to become autonomous learners[1]. Full participation of learner in the teaching learning process and education. and self-management have been promote[2]. Teachers support independent learning as one of 21th century skills. This independent learning first known as self-directed learning. Later, the term of autonomous learning was used. This concept of autonomous learning can be described as the personal initiative in the learning process, such as finding resources and persistence in learning. It is also called self-directed learning[3], which is the ability to obtain knowledge and skills of value independently through processes determined by the individuals[2].

Autonomous learner is influenced by various factors. One important factor is family. According to family systems theorists, the interplay in family relationships is crucial in shaping how individual child's behavior is regulated[4]. In family structure there is siblings in their birth order. The term birth order is typically used to distinguish placement within the family (i.e. first born, second born, and last born). Birth order has long been known in psychological theories to influence the personality of the individuals. The theory of birth order effects was first introduced by Alfred Adler. He defined birth order as the placement within the family into which one is born[5]. The study of the effect of birth order was developed from an assumption that different positions in the sibling order could experience different patterns of interaction with parents and siblings, which may affect the person's development[6].

Theory concerning the effects of birth order has been of interest to researchers since it was first proposed. The results of research about birth order show that birth order can be a factor in 
development throughout one's lifespan. However, there is many controversies around this study. In one side, numerous studies have shown that these effects do in fact exist. For example, one study examined the birth order among psychologists[7]. The findings show that over half of the sample were only children or first-born children. As children, these psychologists had received more attention from their parents than their siblings[6]. Several studies have shown the relationship between firstborns (and only children) and achievement, in terms of both careers and academics [6], [8]-[10]. Futhermore, Chandra (2015) found that there are differences of autonomy between birth order[10]. However, some researchers argued that the concept of interaction between autonomy and birth order to person is weakly supportive[8].

Self-concept is acknowledged as an essential predictor and outcome in educational processes. Previous study show that self-concept can predict future achievement[11]. Unfortunately, the study of correlation between these two factors still rare. This research aims to investigate the effect of birth order and self-concept clarity to toward autonomous learning.

\section{Methodology}

The current study employed survey data from college students $(n=191)$. The surveys were prefaced by an explanation of the study. They were informed that their participations were voluntary and the confidentiality is assured.

\subsection{Measures}

a. Self-Concept Clarity. The Self-Concept Clarity Scale (SCCS) was used to examine how participants defined their self-concept[3]. The SCCS consists of 12 statements to which participants respond on a 5-point scale $(1=$ strongly disagree; $5=$ strongly agree $)$. Higher scores indicating the more clarity of their concept.

b. The Autonomous Learning Scale. The Autonomous Learning Scale was developed by Macaskill and Taylor[12]. It is a 12-item measures on a 5-point Likert scale from 1 (very unlike me) to 5 (very like me).

\subsection{Analysis}

Initially, a covariance analysis (ANCOVA) was conducted for the current study because the data has both continuous and categorical factor. Self-concept clarity and autonomous learning is continuing while birth order is categorical. Analysis was undertaken by SPSS.

\section{Result and Discussion}

The result of this research shown on Table 1.

Table 1. Tests of Between-Subjects Effects (Dependent Variable: Autonomous Learning)

\begin{tabular}{llclll}
\hline \multicolumn{1}{c}{ Source } & Type III Sum of Squares & df & Mean Square & \multicolumn{1}{c}{ F } & Sig. \\
\hline Corrected Model & $1476.131^{\mathrm{a}}$ & 34 & 43.416 & 1.591 & .031 \\
Intercept & 44625.242 & 1 & 44625.242 & $1.635 \mathrm{E} 3$ & .000 \\
Birth Order & .200 & 1 & .200 & .007 & .932 \\
\hline
\end{tabular}




\begin{tabular}{llclcr}
\hline \multicolumn{1}{c}{ Source } & Type III Sum of Squares & df & Mean Square & F & Sig. \\
\hline Self-Concept Clarity & 1461.387 & 33 & 44.284 & 1.622 & .027 \\
Error & 4258.188 & 156 & 27.296 & & \\
Total & 351532.354 & 191 & & & \\
Corrected Total & 5734.319 & 190 & & & \\
a. R Squared =.257 (Adjusted R Squared =.096) & & & & \\
\hline
\end{tabular}

According to table 1 , score of birth order is $.932\left(>.05\right.$, accepting $\left.\mathrm{H}_{0}\right)$ It means that birth order doesn't significantly impact autonomous learning. Score of self-concept clarity is .027 $\left(<.05\right.$, rejecting $\left.\mathrm{H}_{0}\right)$. Means that self-concept clarity significantly impacts the autonomous learning. score of corrected model is .031 $(<.05$, rejecting Ho). It means that simultaneously, birth order and self-concept clarity impact the autonomous learning significantly. Score of $\mathrm{R}$ Squared $=.257$, it means that $25.7 \%$ of birth order and self-concept clarity impact the autonomous learning.

This study shows that the birth order does not significantly influence independence. However, this study shows a positive (on a small scale) effect of the birth order on independence. The results of this study are different from previous studies which suggested that there were significant differences in adolescent independence in terms of birth order. Researchers suspect that the most influential factors in forming adolescent independence are the role of parents and adults around them, as well as education that always encourages adolescents to achieve their independence.

Independency can be influenced by various factors. Internal and external factors in a person that will greatly influence independency in everyone[13]. Internal factors, such as: age, gender, level of education, self-concept, self-esteem, and styles of interacting with others, while external or environmental factors, such as: family, activities or work, relationships with parents, peers, teachers and cultural background. External factors and internal factors also play a role in the formation of independence in each individual. This study focused on self-concept which becomes an internal factor different levels of independence for each student.

Fitts (1971) explained that self-concept is as a whole awareness or perception of oneself being invaded, experienced, and judged by an individual[14]. He explained that when an individual perceives himself, reacts to himself, meaning he shows a self-awareness (selfawareness) and the ability to get out of himself to see himself as he did with the world outside himself. The self-concept that exists in each individual is formed through the process of his life journey, so it is not an innate birth. Someone who has a high self-concept then he will do something positive as well and be confident in the abilities that he has, so that this can make the basis for being able to live more independently. Conversely, if indeed an individual has a low self-concept, it is feared he will not be able to regulate his life independently because he is still very dependent on others. Therefore, self-concept can influence independence as evidenced by this study.

Based on descriptive analysis carried out in this study with the aim to obtain an overview of the hypothesis in the study. After the descriptive analysis was carried out, the data for the self-concept variable from 191 respondents found 27 respondents $(14.13 \%)$ included in the low category, 132 respondents $(69.10 \%)$ included in the moderate category, and 32 respondents $(16.75 \%)$ included in the high category. This shows the self-concept of the participants were in the medium category, this explains that every student has independence even in a different range. Factors that influence self-concept are other people's factors and reference group factors[3]. Usually people who can influence one's self-concept are the people closest to him, have emotional ties, such as family. As stated by Sullivan that if we are accepted by others, respected, and liked because of our condition, we will tend to be respectful 
and accept ourselves. Conversely, if other people always underestimate us, blame and reject us, then we tend to hate ourselves as well.

\section{Conclusion}

The findings of this study show a small effect of birth order on autonomous learning and a strong impact on self-concept. This study supports previous studies which explained the interaction between birth order, self-concept, and autonomous learning. Future study could expand the number of participants and the scope of research to obtain a more comprehensive data.

\section{References}

[1] Macaskill A and Taylor E, 2010 The development of a brief measure of learner autonomy in university students Stud. High. Educ. 35, 3 p. 351-359.

[2] Chene A, 1983 The concept of autonomy in adult education: A philosophical discussion Adult Educ. Q. 34, 1 p. 38-47.

[3] Campbell J D Trapnell P D Heine S J Katz I M Lavallee L F and Lehman D R, 1996 Self-Concept Clarity: Measurement, Personality Correlates, and Cultural Boundaries $J$. Pers. Soc. Psychol. 70, 1 p. 141-156.

[4] Cox M J and Paley B, 1997 Families as systems Annu. Rev. Psychol. 48, 1 p. 243-267.

[5] Abramson Z, 2016 Freud and Adler: Differences. J. Individ. Psychol. 72, 2 p. 140-147.

[6] Combs-Draughn A J, 2016, The impact of psychological birth order on academic achievement and motivation, Walden University.

[7] Simonton D K, 2008 Gender Differences in Birth Order and Family Size Among 186 Eminent Psychologists J. Psychol. Sci. Technol. 1, 1 p. 15-22.

[8] Stewart A E and Eckstein D, 2012 Birth order within individual psychology J. Individ. Psychol. 68, 1 p. 1-3.

[9] Summers K, 1999, Evolutionary psychology, birth order and family dynamics, Trends in Ecology and Evolution, 14, 3. p. 86-87.

[10] Campbell L White J and Stewart A, 2005, The relationship of psychological birth order to actual birth order, in Readings in the Theory of Individual Psychology, p. 325-335.

[11] Marsh H W and O'Mara A, 2008 Reciprocal effects between academic self-concept, self-esteem, achievement, and attainment over seven adolescent years: Unidimensional and multidimensional perspectives of self-concept Personal. Soc. Psychol. Bull. 34, 4 p. 542-552.

[12] Macaskill A and Denovan A, 2013 Developing autonomous learning in first year university students using perspectives from positive psychology Stud. High. Educ. 38, 1 p. 124-142.

[13] Oudeyer P Y Kaplan F and Hafner V V., 2007 Intrinsic motivation systems for autonomous mental development IEEE Trans. Evol. Comput. 11, 2 p. 265-286.

[14] Marsh H W and Craven R, 1997, Academic Self-Concept: Beyond the Dustbowl, in Handbook of Classroom Assessment. Learning, Achievement and Adjustment, p. 131198. 